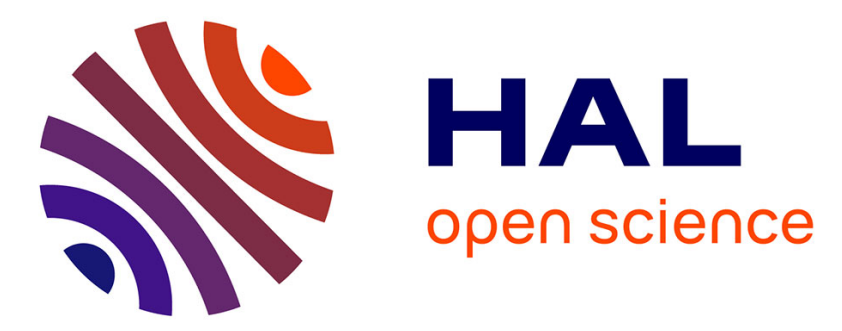

\title{
Complementary characterization methods for Lithium-ion Polymer secondary battery modeling
}

Nathalie Devillers, Marie-Cécile Péra, Samir Jemei, Frédéric Gustin, Daniel

Bienaime

\section{- To cite this version:}

Nathalie Devillers, Marie-Cécile Péra, Samir Jemei, Frédéric Gustin, Daniel Bienaime. Complementary characterization methods for Lithium-ion Polymer secondary battery modeling. International Journal of Electrical Power \& Energy Systems, 2015, 67, pp.168-178. 10.1016/j.ijepes.2014.11.020 . hal-02130978

\section{HAL Id: hal-02130978 \\ https://hal.science/hal-02130978}

Submitted on 21 Oct 2021

HAL is a multi-disciplinary open access archive for the deposit and dissemination of scientific research documents, whether they are published or not. The documents may come from teaching and research institutions in France or abroad, or from public or private research centers.
L'archive ouverte pluridisciplinaire HAL, est destinée au dépôt et à la diffusion de documents scientifiques de niveau recherche, publiés ou non, émanant des établissements d'enseignement et de recherche français ou étrangers, des laboratoires publics ou privés.

\section{(c)(1)}

Distributed under a Creative Commons Attribution| 4.0 International License 


\title{
Complementary characterization methods for Lithium-ion Polymer secondary battery modeling
}

\author{
Nathalie Devillers ${ }^{\mathrm{a}, *}$, Marie-Cécile Péra ${ }^{\mathrm{b}, 1}$, Samir Jemei ${ }^{\mathrm{b}, 2}$, Frédéric Gustin ${ }^{\mathrm{b}, 3}$, Daniel Bienaimé ${ }^{\mathrm{a}}$ \\ ${ }^{a}$ FEMTO-ST Institute, Energy department, UMR CNRS 6174, Rue Thierry Mieg, Techn'hom, 90010 Belfort Cedex, France \\ ${ }^{\mathrm{b}}$ University of Franche-Comte, FEMTO-ST Institute, UMR CNRS 6174, Rue Thierry Mieg, Techn'hom, 90010 Belfort Cedex, France
}

\begin{abstract}
This paper deals with the electrical modeling of Lithium-ion Polymer battery, from complementary char-acterization tests. The first aim of this work is to understand the electrical behavior of this battery through experimentations in the same environmental conditions as the final application's ones. The second goal of this work is to identify battery models with different precision levels and to implement them in specific models of the considered aircraft electrical network. In this paper, two equivalent electrical circuit models are presented: a quasi-static model, which is functional and sufficient for the electrical energy management in the aircraft; a dynamic model, which is behavioral and necessary for the analysis of the embedded network quality. The identification of their parameters is carried out with adapted char-acterization tests, such as chronopotentiometry at constant current and Electrochemical Impedance Spectroscopy at different temperatures. The complementarity of these tests is particularly underlined in this paper because it is useful for the parameter identification. The results from model simulation and from experimentation are compared through a mission profile and are analyzed. Eventually, this paper presents complete experimental data for a commercial 4.8 Ah Lithium-ion Polymer battery includ-ing the temperature influence.
\end{abstract}

\section{Introduction}

The management of an embedded electrical network requires the use of electrical storage systems, such as battery, in order to guarantee the network stability and quality, and the energy availability. In conventional aircrafts, electrical storage systems are helpful as support to engine start at the mission beginning or as electrical emergency back-up. For a couple of years, aircrafts have moved on "more electrical" aircrafts [1] due to the flexibility of use of electrical energy and due to the decrease of its operating cost. This evolution implies a higher consumption of electrical energy and a change of functional scope for storage systems.

As battery is considered as an energy source in regards to the application scale [2], it is necessary to know its electrical behavior in the aircraft environmental conditions. Therefore, battery must

\footnotetext{
* Corresponding author. Tel.: +33 3845836 57; fax: +33 384583636 .

E-mail addresses: nathalie.devillers@femto-st.fr (N. Devillers), marie-cecile. pera@univ-fcomte.fr (M.-C. Péra), samir.jemei@univ-fcomte.fr (S. Jemei), frederic. gustin@univ-fcomte.fr (F. Gustin).

1 Tel.: +33 384583623 .

2 Tel.: +33 384583641 .

3 Tel.: +33 384583617 .
}

be characterized with a view to be modeled in a tractable way, in order to carry out numerical simulations and to anticipate its operation within the aircraft network.

\section{Battery characteristics}

This paper deals with a Lithium-ion Polymer battery. Their main characteristics are summed up in this paragraph. One of these characteristics is the Open-Circuit Voltage (OCV). This voltage is due to the redox potential difference between the electrode materials. For Lithium-ion Polymer battery, the nominal open-circuit voltage is about $3.7 \mathrm{~V}$ a cell. Another characteristic is the capacity, that is the quantity of charges that battery can provide (under constant voltage) during discharge time. The capacity range of Lithium-ion Polymer battery is between few Ah and few hundreds of Ah. The quantity of specific energy is in connection with both previous characteristics and in relation to the battery volume or weight. The major advantage of Lithium-ion Polymer battery is its high specific energy [3,4], which is about $120-180 \mathrm{Wh} \cdot \mathrm{kg}^{-1}$ or 200-300 Wh.dm ${ }^{-3}$, and its specific power, which is between 10 and $1000 \mathrm{~W} \cdot \mathrm{kg}^{-1}$. Its discharge time is about several minutes or hours, it depends especially on the discharge current-rate. The life duration of Lithium battery is higher than life duration of other 
battery technologies (Nickel or Lead). However, its number of cycles, which is about $1000-1500$ cycles for a depth of discharge (DOD) of $80 \%$, is rather low in comparison with other Energy Storage Systems. The life duration is the main drawback of Li-ion battery. Moreover, this kind of battery has also two advantages: an excellent energetic efficiency (close to $100 \%$ because of the non-aqueous electrolyte) and a low auto-discharge rate, which is between $0.1 \%$ and $0.5 \%$ a day.

The tested battery cells are provided by Kokam (Fig. 1). According to the datasheet [5], the nominal capacity is $4.8 \mathrm{Ah}$, the nominal voltage is $3.7 \mathrm{~V}$ and its maximal value is $4.2 \mathrm{~V}$. The tested cell is classified as a high power density cell, where its specific power is higher than $2 \mathrm{~kW} \cdot \mathrm{kg}^{-1}$ and its specific energy is about 155 Wh. $\mathrm{kg}^{-1}$.

One of the aims of this paper is to give complete experimental data for this commercial high power battery including the temperature influence on its performance.

\section{Battery modeling}

Numerous models of battery are developed in literature [6]: electrochemical models and equivalent electrical circuit models. On Li-ion batteries, several models were developed. For instance, in [7], a mathematical model is developed to predict time response of battery in charge and at constant temperature. Another example is given in [8], where the diffusion phenomenon is modeled by a capacitive transmission line. In this case, the study focuses on electrode porosity and on concentration at the electrodes/electrolyte interfaces. A $\mathrm{LiFeO}_{4}$ battery model is simulated in [9], for a PNGV (Partnership for a New Generation of Vehicles) application. On Li-ion Polymer ( $\mathrm{Li}-\mathrm{Po})$ batteries, some models with electrical equivalent circuits were established recently. The model parameters are mathematically defined in function of temperature and state-of-charge [10,11]. In [12], a simple model is developed with linear parameters and nonlinear parameters (such as hysteresis phenomenon).

In this paper, the studied models are based on equivalent electrical circuits, according to the analogy between electrochemical and electrical fields. The global model implementation and its final use lead to a relevant choice of modeling and model granularity. Hence, two equivalent electrical circuit models are retained in this paper: a quasi-static model, which is simple, functional and sufficient for studying the battery operation during a mission profile; and a dynamic model, which is behavioral and necessary for studying the battery performance at transient steps and for the accurate analysis of the network quality.

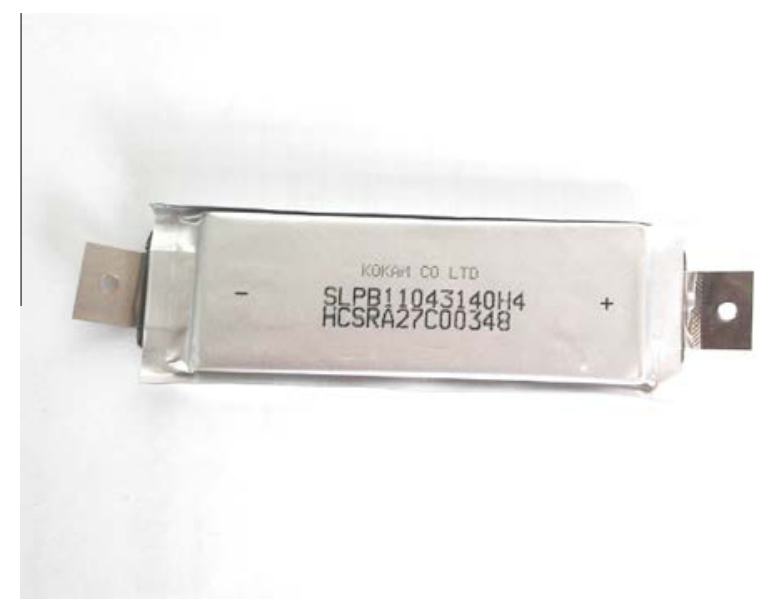

Fig. 1. Example of a Kokam Lithium-ion Polymer 4.8 Ah cell.
The parameters of these different models can be determined through experimentations with adapted characterization methods.

\section{Battery characterization}

In literature, battery characterization tests are used to describe and to comprehend their electrical behavior at steady-state and in transient operation. They are based on several tests such as charge/ discharge cycle tests at different current rates [13] and on Electrochemical Impedance Spectroscopy (EIS) [10,14]. In general [15], the kind of the characterization test depends on the method chosen for the analysis. For instance, time domain analysis needs experimental data such as voltage and current from charge and discharge tests. Another example, frequency domain analysis is carried out through Nyquist plots, which are obtained by impedance measurements (typically EIS).

Furthermore, investigations are usually carried out in different conditions in order to study the battery behavior and its evolution with state-of-charge [10,8], current rate [8], temperature [10,11], use frequency and cycling (or ageing).

In this paper, two equivalent electrical models are chosen according to their future use: a quasi-static model and a dynamic model. As these are models used in time domain, the Lithium-ion Polymer battery cells are characterized by using a chronopotentiometry at constant current. Moreover, the dynamic model is composed of complex impedance and its determination needs EIS. Otherwise, characterizations are carried out in experimental conditions which define the validity area of modeling, in relation with the application constraints. Hence, this study focuses on stateof-charge and temperature because their influence on model parameters is dominating.

Then, these models are assessed through a comparison of simulation and experimental results in response to a load profile, defined from aircraft mission profiles.

Finally, the experimental results are presented, analyzed and compared.

\section{Experimentation and modeling}

Firstly, charge and discharge tests at constant current are carried out to determine the battery capacity and to compare it with supplier's data.

\section{Determination of battery capacity}

\section{Test procedure}

Method. The test procedure consists in supplying the discharged battery with a constant current corresponding to $1 \mathrm{C}$-rate, until the voltage reaches its maximal value, which is $4.2 \mathrm{~V}$. Then the battery voltage is regulated at its maximum value until the charging current tends to zero. At that time, the battery is considered as charged. Finally the battery is discharged by providing a constant current until the voltage equals its minimum value, which is 2.7 V (Fig. 2). Three tests are carried out with three values for the discharge current $I_{b a t}$ corresponding to $0.5 \mathrm{C}, 1 \mathrm{C}$ and $2 \mathrm{C}$ rates.

Determination of capacity. As it is easier to know when the battery is completely charged, the capacity $C_{n}$ (in Ah) is determined, according to (1), from a discharge test at constant current $I_{\text {bat }}$ (in A) after a complete charge as described before (Fig. 3).

$C_{n}=\left(\int I_{b a t} \cdot d t\right) / 3600$

\section{Results}

The stored capacity, measured during discharge period, is about 4.15 Ah (at 2 C-rate), 4.2 Ah (at $1 \mathrm{C}$-rate) and 4.3 Ah (at 0.5 C-rate). 


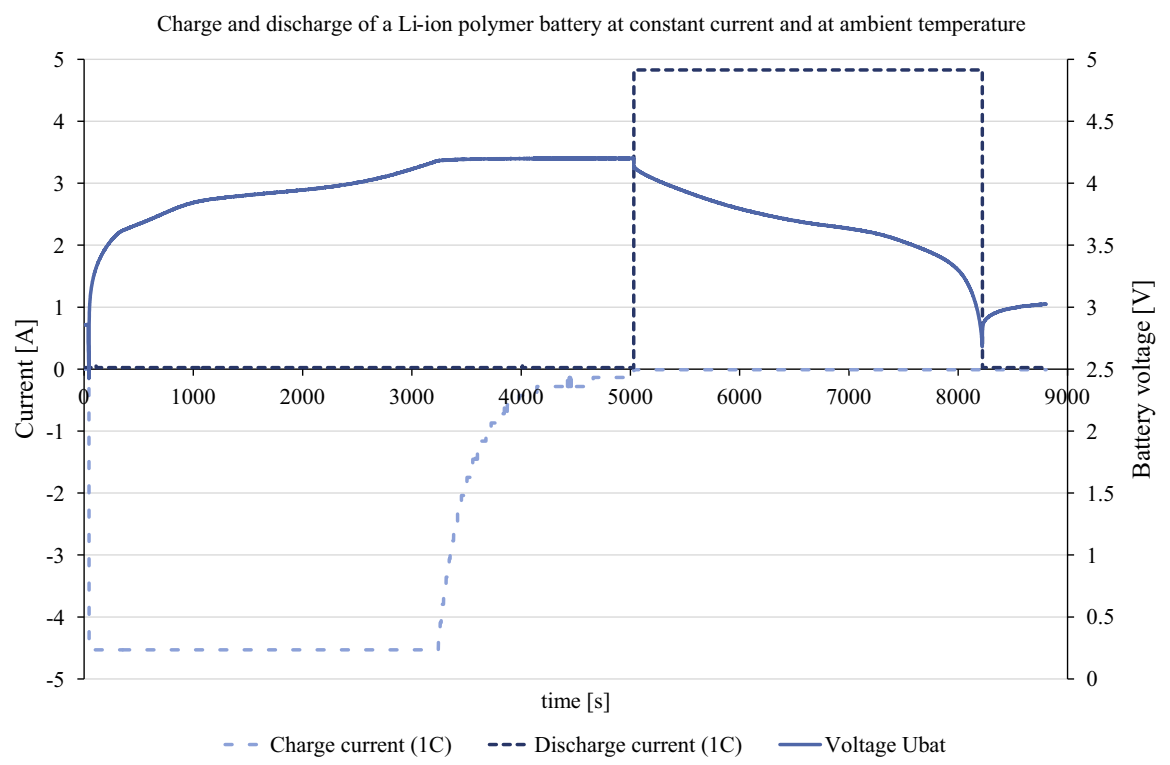

Fig. 2. Complete charge and discharge for capacity determination at ambient temperature.

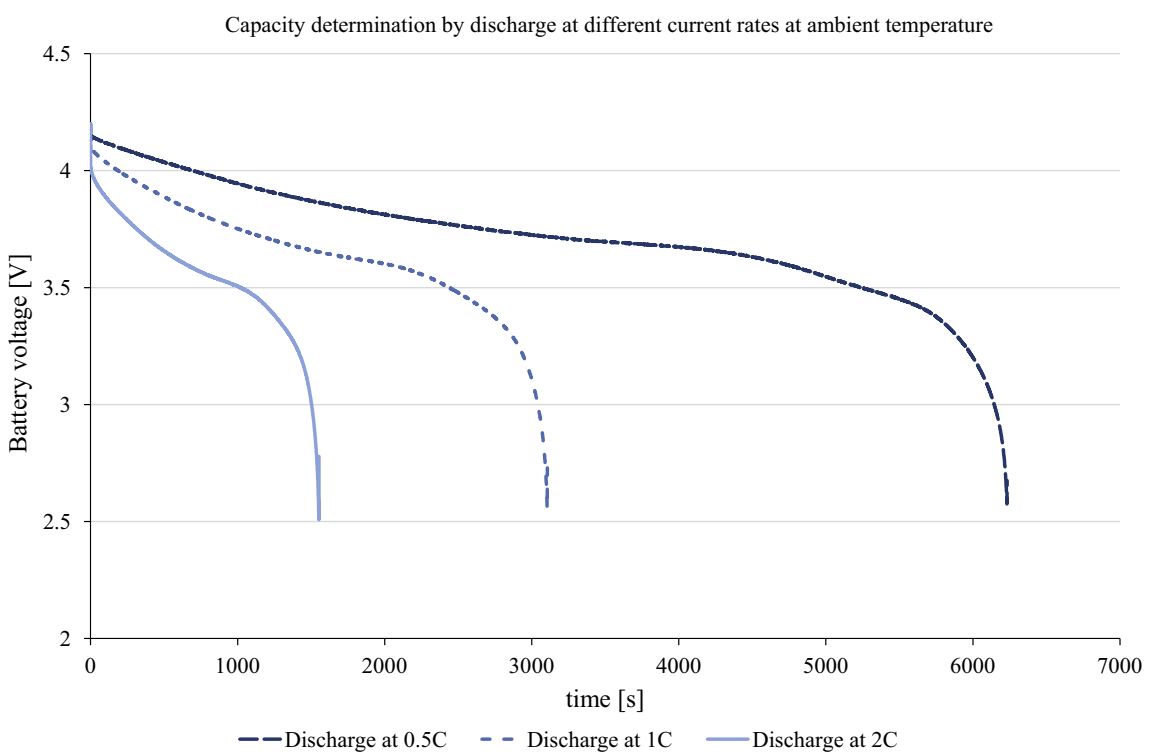

Fig. 3. Capacity determination by discharge at different current-rates at ambient temperature.

In comparison with the nominal capacity indicated by supplier at 0.5 C-rate, the measured capacity is rather low. Nevertheless, as results are in good agreement within the three discharge tests, the stored capacity $C_{n}$ is considered to be $4.3 \mathrm{Ah}$ at $20^{\circ} \mathrm{C}$. On the other hand, the specific energy obtained by measuring is around 137 Wh. $\mathrm{kg}^{-1}$ at 0.5 C-rate, whereas the energy density specified by battery's supplier is about $155 \mathrm{Wh} . \mathrm{kg}^{-1}$. This gap is in relation with the gap noticed on capacity.

After the determination of the battery capacity, a short definition of each model is given and the associated test procedure is described in the next paragraphs.

\section{Experimentation for quasi-static model determination}

Description and field of application of quasi-static model

The quasi-static model (Fig. 4), also called Thevenin model [16], is a basic electrical circuit, composed of an Equivalent Serial Resistance (ESR) $R_{b a t}$ and an Open-Circuit Voltage (OCV) $E_{t h}$. The open-circuit voltage corresponds to the battery voltage at its thermo-dynamic equilibrium.

The quasi-static model is a functional model, usually used for global management of embedded energy [17,18]. This model represents the energetic behavior of the battery. It can be improved by taking into account various dependence on stateof-charge (SOC) [17], temperature and current rate [18]. In these different cases, variations of the open-circuit voltage and the

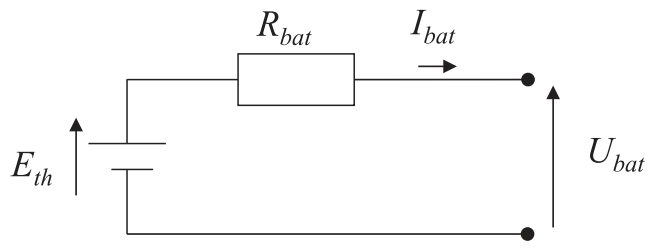

Fig. 4. Equivalent electrical circuit for quasi-static model 
internal resistance are modeled with a look-up table or a mathematical formula describing their relation. In this paper, the model parameter dependence on state-of-charge and on temperature is studied.

\section{Test procedure}

Discharge tests by means of current steps were carried out in order to identify the model parameters.

Method. Previously, the battery is completely charged according to the method previously described for the capacity determination. Then the cell is discharged by applying current steps (at constant current equivalent to $1 \mathrm{C}$-rate), in order to reach different states-of-charge. At the end of each step, the battery voltage $U_{b a t}$ is measured. After a stabilization period of several minutes (the equilibrium is reached when the voltage variation is less than $0.1 \%$ ), the open-circuit voltage $E_{t h}$ is measured (Fig. 5).

Test conditions. The tests are carried out at three temperatures: $0{ }^{\circ} \mathrm{C}, 20^{\circ} \mathrm{C}$ and $40^{\circ} \mathrm{C}$. The minimal and maximal ones are in relation with the operating temperatures indicated in the supplier's datasheets [5].

\section{Identification of the quasi-static model parameters}

Determination of the open-circuit voltage $E_{t h}$. The OCV is measured at different states-of-charge and temperatures when the battery voltage is stable. The state-of-charge SOC (per unit) is determined from the recovered capacity $C_{u}$ (in Ah) during the discharge period and from the initial state-of-charge $S_{0} C_{0}$ (p.u.), as defined in (2).

$S O C=S O C_{0}-C_{u} / C_{n}$

Determination of the equivalent serial resistance $R_{b a t}$. For different states-of-charge, the battery voltage $U_{b a t}$ (in $\mathrm{V}$ ) and the opencircuit voltage $E_{t h}$ (in $\mathrm{V}$ ) are measured and then, the internal resistance $R_{\text {bat }}$ (in $\Omega$ ) is deduced through (3).

$R_{b a t}=\left(E_{t h}-U_{b a t}\right) / I_{b a t}$

\section{Results of characterization and simulation}

On the one hand, the evolution of the open-circuit voltage versus state-of-charge is given in Fig. 6 at different temperatures.
There is no impact of temperature on OCV. This evolution of $E_{t h}$ (in V) versus SOC (p.u.) can be approached by a mathematical relation (4).

$E_{\text {th }}=5.1 \cdot S^{3} C^{3}-8.8 \cdot S^{2} C^{2}+5.1 \cdot S O C+2.8$

On the other hand, the evolution of $R_{b a t}$ versus SOC can also be observed (Fig. 7). The influence of temperature on the internal resistance is significant. The serial resistance $R_{b a t}$ increases when temperature and state-of-charge decrease. When SOC (p.u.) is between 0.3 and $1, R_{b a t}$ at $40^{\circ} \mathrm{C}$ equals the half of $R_{b a t}$ at $20^{\circ} \mathrm{C}$ and $R_{\text {bat }}$ at $0{ }^{\circ} \mathrm{C}$ is twice $R_{\text {bat }}$ at $20^{\circ} \mathrm{C}$.

A comparison between experimental results and simulation of the quasi-static model with MATLAB-Simulink ${ }^{\circledR}$ is presented in Fig. 8. The gaps observed between experimentation and simulation results are of the same order of magnitude, whatever temperature is. The serial resistance, as determined in (3), induces a voltage drop which is quite overrated, all the more at low state-of-charge.

To conclude, the quasi-static model is suitable for representing the steady-state operation of the battery cell, in that it takes into account temperature influence and the evolution of the opencircuit voltage versus state-of-charge. Nevertheless, its basic impedance is not adapted to represent the various phenomena into the battery in transient period, such as charge transfer and diffusion phenomena. That is why a dynamic model is developed afterwards.

\section{Experimentation for dynamic model determination}

\section{Description and field of application of dynamic model}

The fundamental electrochemical interface model (Fig. 9) is a common model which describes the electrical behavior of batteries more accurately than the quasi-static model. Randles developed an impedance model of the electrochemical interface [19]. The modification of the Randles equivalent circuit leads to a lot of dynamic models, which describe dynamic phenomena, in particular charge transfer and diffusion. In fact, the Randles model can be simplified by dividing the faradic impedance $Z_{f}$ in two impedances (Fig. 10a): one for charge transfer and one for diffusion. The simplified Randles model can also be represented such as in Fig. 10b, by considering the charge transfer time constant is quite the same as the time constant of double-layer phenomenon, and is smaller than the diffusion's one [20].

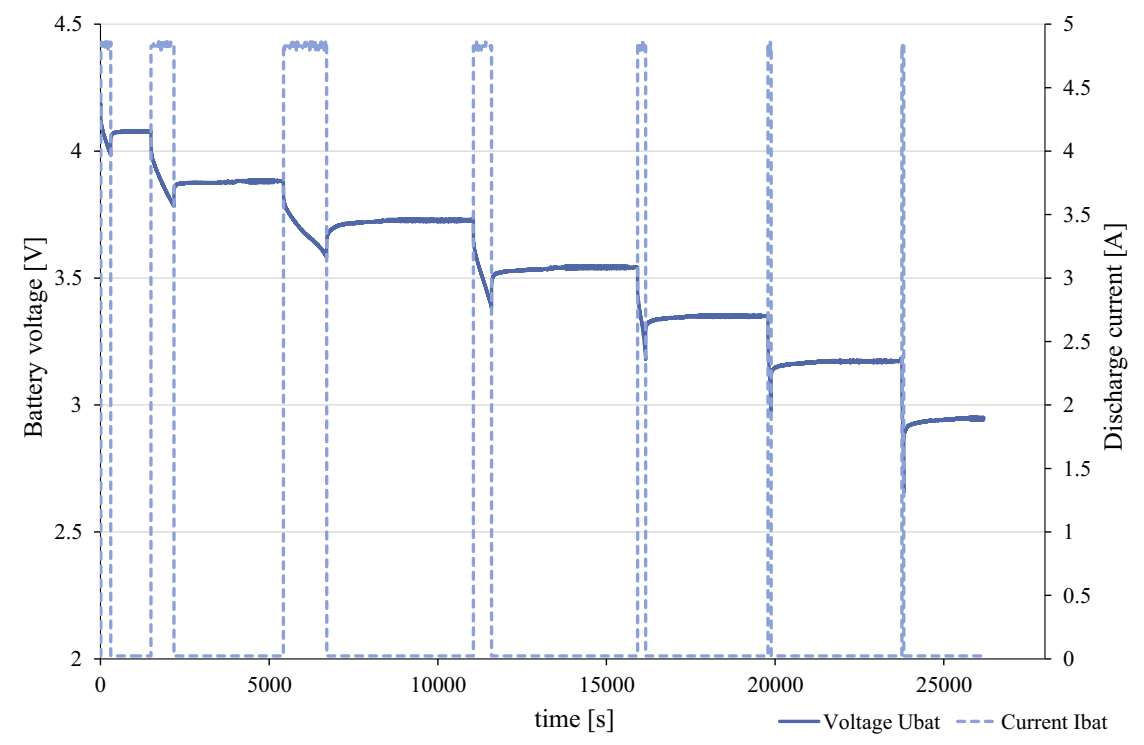

Fig. 5. Evolution of current and voltage during the discharge test at $20^{\circ} \mathrm{C}$. 


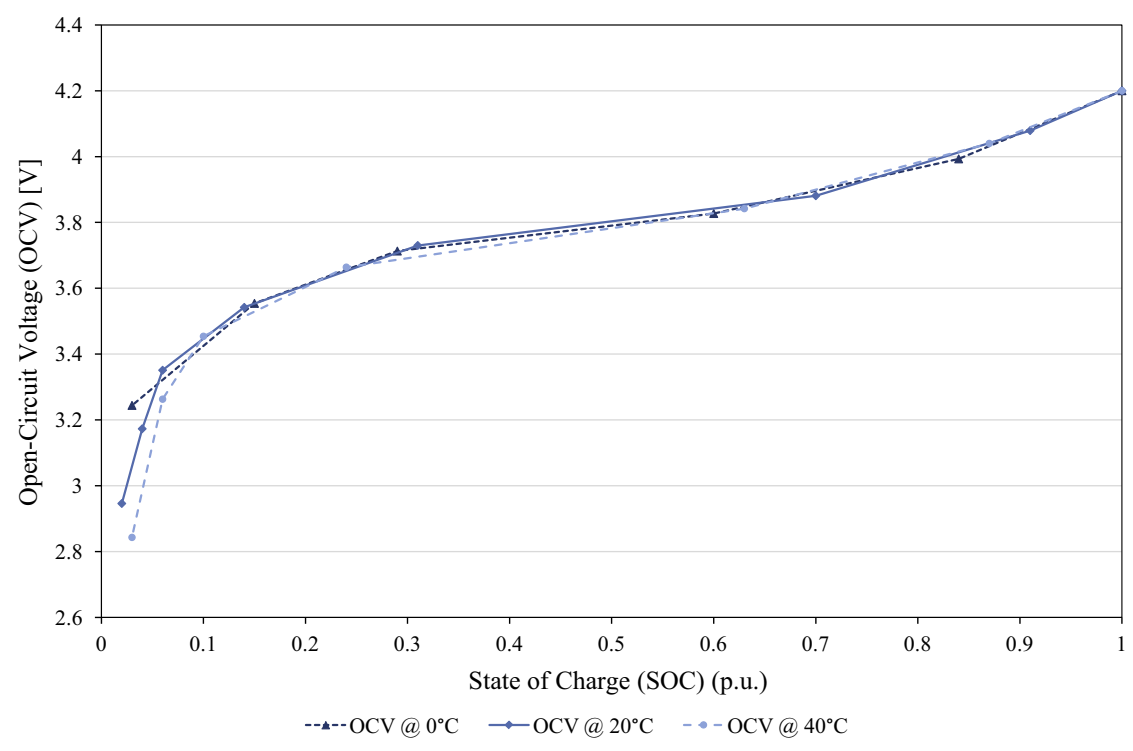

Fig. 6. Evolution of Open-Circuit Voltage (OCV) versus state-of-charge (SOC) at different temperatures.

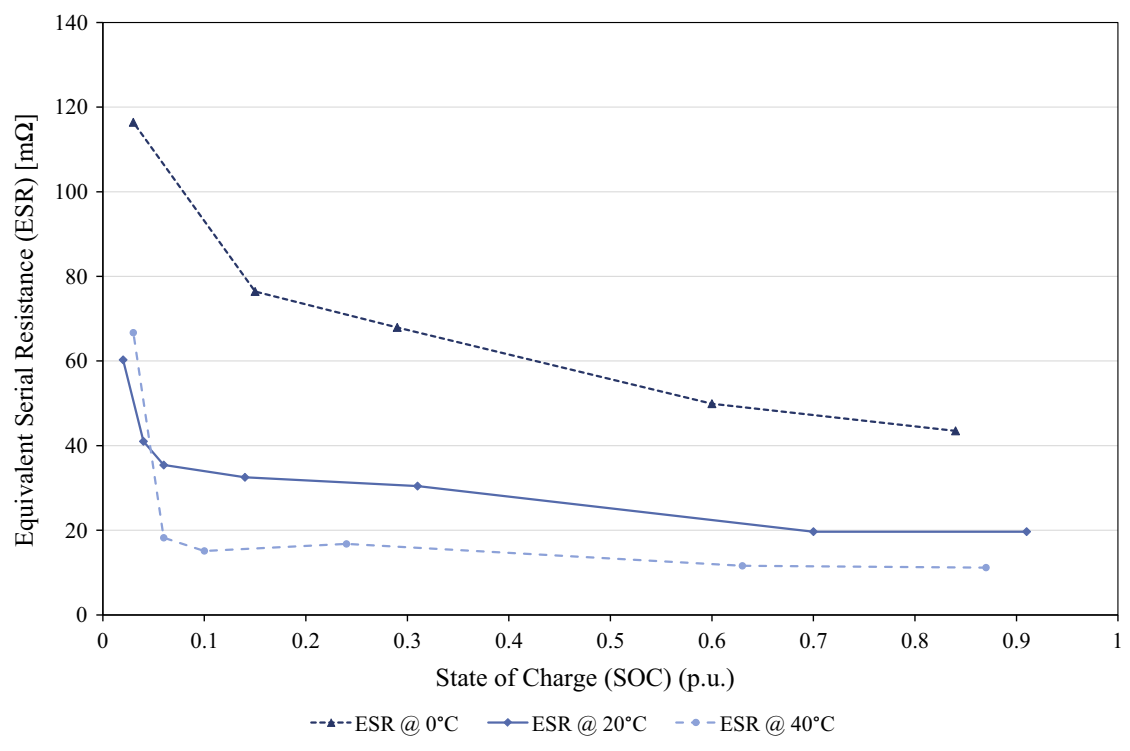

Fig. 7. Evolution of Equivalent Serial Resistance (ESR) versus state-of-charge (SOC) at different temperatures.

The dynamic model, presented in this paper, is based on the simplified Randles model. As shown in Fig. 11, it is an electrical circuit with an open-circuit voltage $E_{t h}$ and a complex impedance. This one is composed of: - a serial resistance $R_{\Omega}$ representing the pure ohmic resistance of the electrolyte and electrodes, - an electrolytic double-layer capacitor $C_{d l}$ in parallel with a charge transfer resistance $R_{c t}$, - an impedance $Z_{d}$ representing the diffusion phenomenon. The inductive behavior of the component in high frequencies is modeled by an inductance $L_{f}$.

The diffusion phenomenon describes the consumption or the production of species at the electrodes/electrolyte interfaces. Chemical diffusion is the transport of species under a chemical potential gradient. To model this phenomenon, three hypotheses are usually considered [21]: the Nernst hypothesis in which the diffusion layer is limited to a fixed distance and there is an ideal reservoir at the boundary; the Warburg hypothesis in which the diffusion layer is unlimited; and a third hypothesis in which the diffusion layer is limited and there is a non-permeable wall at the boundary. These three hypotheses are in relation with three impedances, which have a different behavior at very low frequencies (diffusion phenomenon), but have the same behavior at higher frequencies. In this paper, the Nernst hypothesis is considered and its related impedance is given in (5).

$Z_{d_{-N} \text { Nernst }}(p)=R_{d} \cdot \tan h\left(\tau_{d} \cdot p\right)^{1 / 2} /\left(\tau_{d} \cdot p\right)^{1 / 2}$

Nernst impedance can be approached by a finite sum of $R-C$ circuits, such as in the Foster or Cauer structures [20]. The expression of the Foster structure is given in (6) and the equivalent electrical circuit is detailed in Fig. 12.

$Z_{\text {Foster }}(p)=\sum\left(R_{n} /\left(1+R_{n} \cdot C_{n} \cdot p\right)\right) ; n \in[1 ;+\infty[$

This dynamic model describes the behavior of battery on a large frequency range. Hence this model can be used for the simulation and the analysis of the battery transient behavior. 

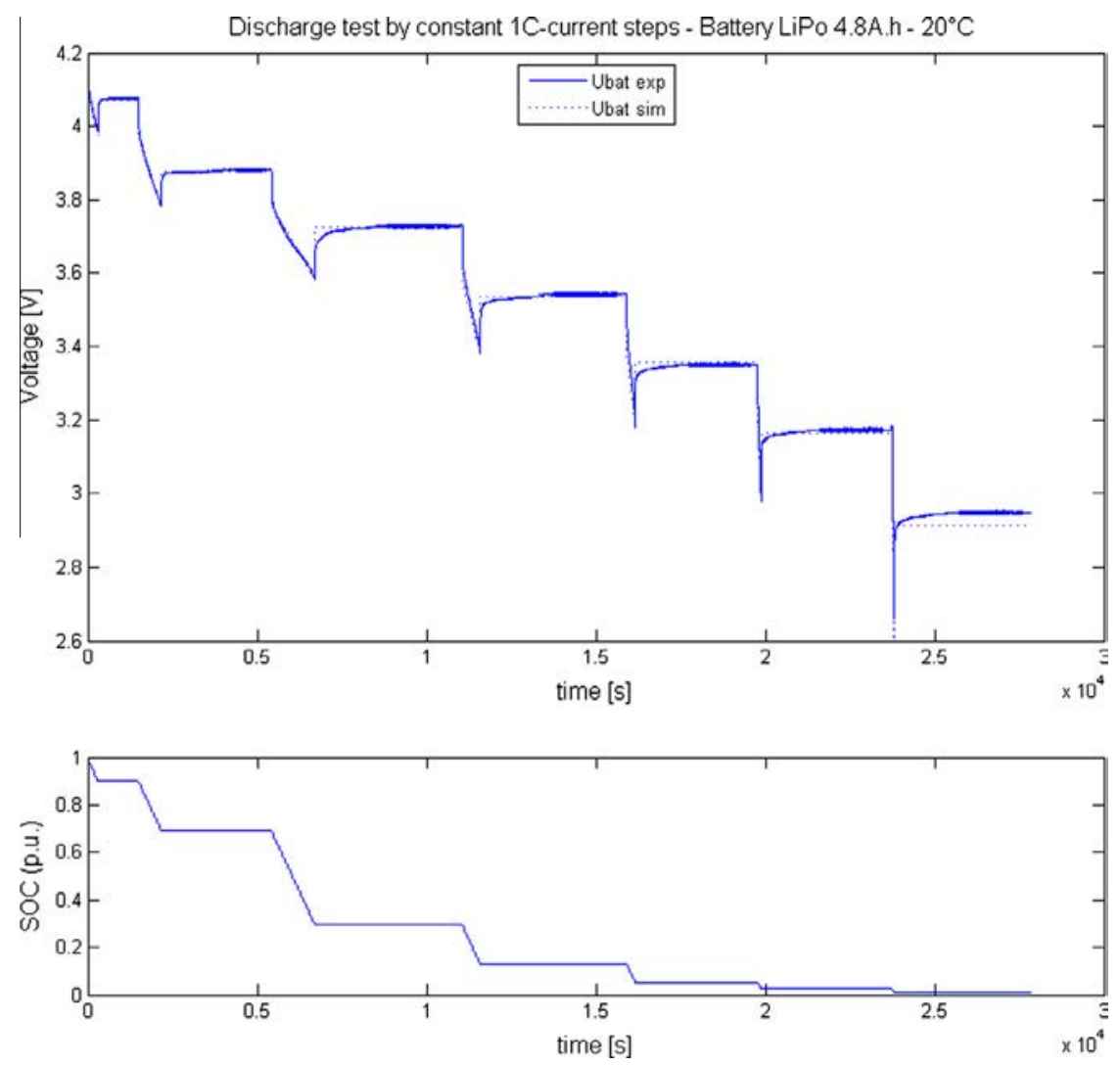

Fig. 8. Comparison between experimentation and quasi-static model simulation: discharge test by constant $1 \mathrm{C}$-current steps at $20^{\circ} \mathrm{C}$.

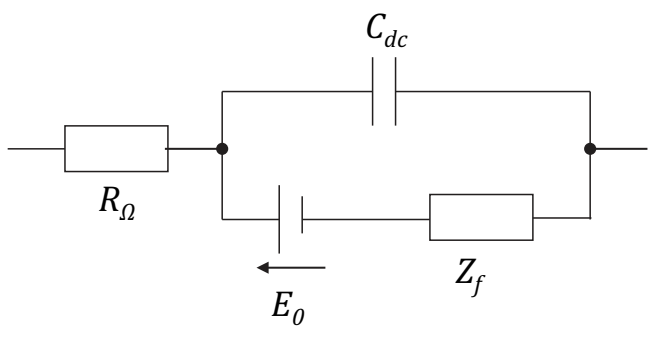

Fig. 9. Fundamental electrochemical model of electrolyte/electrode interface.

\section{Test procedure}

The test procedure associated to the dynamic model is an Electrochemical Impedance Spectroscopy (EIS) [14]. This test focuses on the harmonic response of the tested battery, and particularly on the evolution of its impedance against frequency.

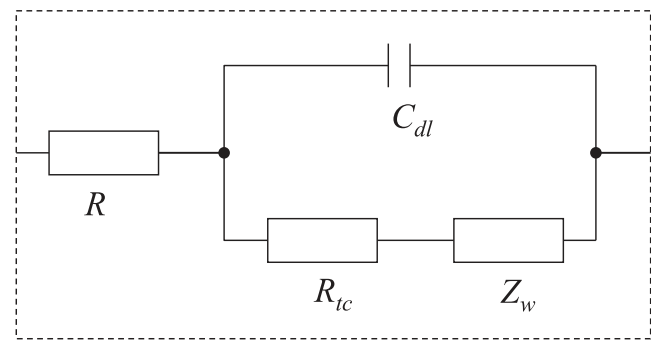

a

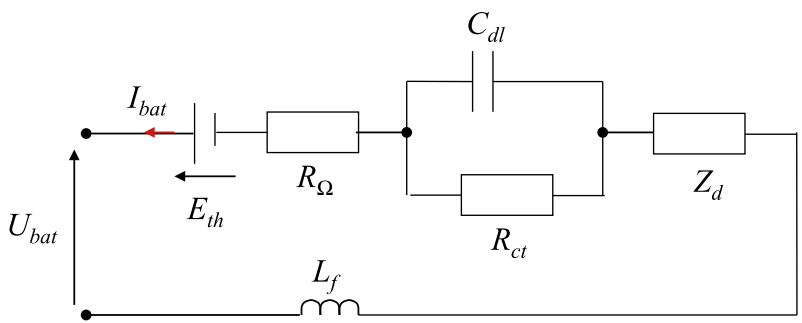

Fig. 11. Equivalent electrical circuit for dynamic model.

Method. This test is carried out with a Zahner IM6 impedance spectrometer which provides a sinusoidal signal with low amplitude and variable frequency. When the battery is stabilized to an open-circuit voltage corresponding to a certain state-of-charge, a sinusoidal voltage is applied around the polarization voltage. This

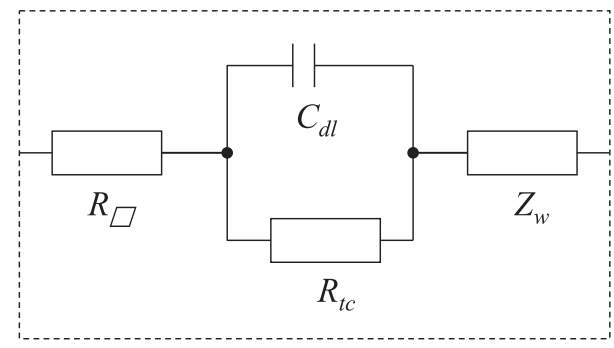

b

Fig. 10. (a) Impedance from Randles electrochemical interface model - (b) Simplified impedance model from Randles model. 


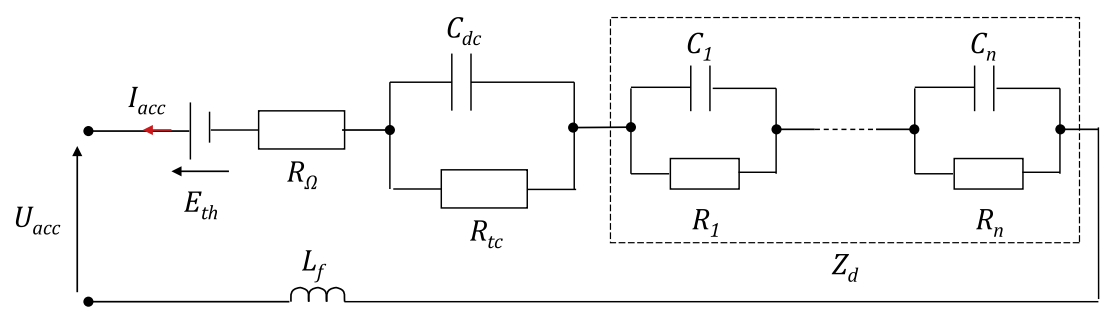

Fig. 12. Equivalent electrical circuit for dynamic model with Foster structure for diffusion impedance.

method is called potentio-static spectrometry. According to [14], few authors consider that EIS performed in potentio-static mode is not representative because electrochemical phenomena during the equilibrium period are different to those during a charge or discharge period. They suggest another method, in galvano-static mode, during the charge or the discharge of the battery. This process of impedance spectroscopy introduces measurement errors. Even though many improvements were studied to remedy this problem, errors remain significant at low frequencies. As a matter of fact, EIS in potentio-static mode is the most widely used method [14]; that is why spectrometry is carried out in this way. The amplitude of the sinusoidal voltage is usually under $10 \mathrm{mV}$ [14]. For this study, the voltage is $5 \mathrm{mV}$, in order to ensure that the current induced by the sinusoidal voltage is lower than $10 \%$ of the nominal current. The frequency range is between $20 \mathrm{mHz}$ and $10 \mathrm{kHz}$, this frequency range is often used [11].

Test conditions. The tests were carried out at three temperatures: $0{ }^{\circ} \mathrm{C}, 20^{\circ} \mathrm{C}$, and $40{ }^{\circ} \mathrm{C}$.

\section{Identification of the dynamic model parameters}

Determination of the open-circuit voltage $E_{t h}$. The OCV is measured at different states-of-charge and temperatures when the battery voltage is stable. The evolution of $E_{t h}$ versus SOC at different temperatures, presented in the previous paragraph, is still valid.

Determination of the complex impedance. The identification of the impedance parameters is carried out from a harmonic analysis of impedance spectra. The gap $\varepsilon$ between real and imaginary parts

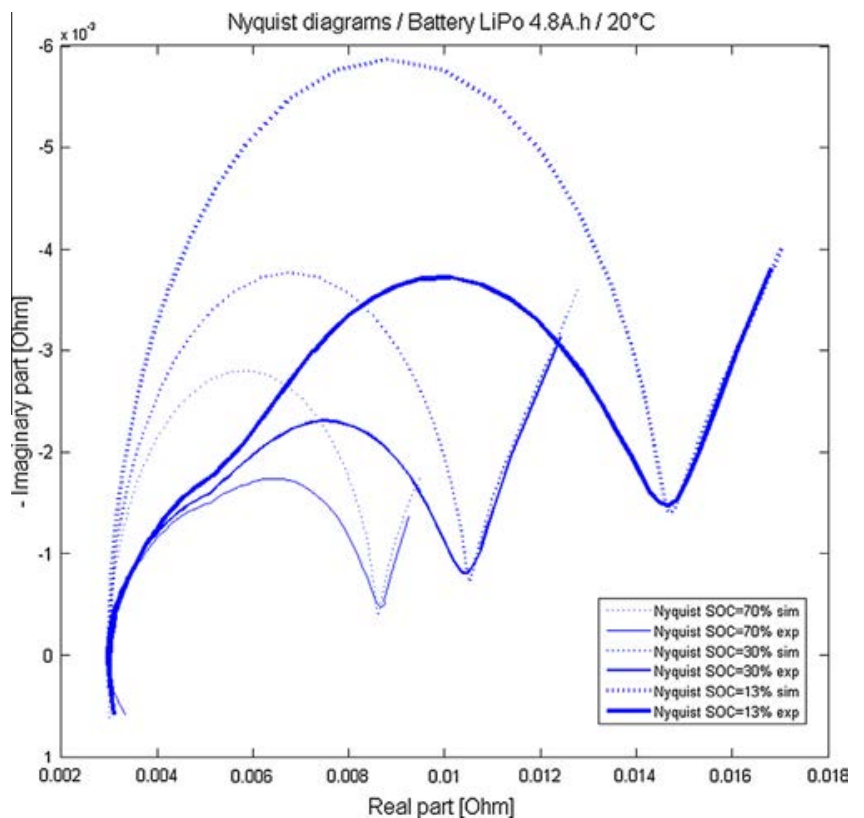

Fig. 14. Comparison between experimentation and simulation results in frequency domain (at $20^{\circ} \mathrm{C}$ ).

from experimentation and simulation is minimized by the leastsquares method (7).

$$
\varepsilon=\sum\left[\left(\operatorname{Re}\left(Z_{\text {exp }}\right)-\operatorname{Re}\left(Z_{\text {mod }}\right)\right)^{2}+\left(\operatorname{Im}\left(Z_{\text {exp }}\right)-\operatorname{Im}\left(Z_{\text {mod }}\right)\right)^{2}\right]
$$

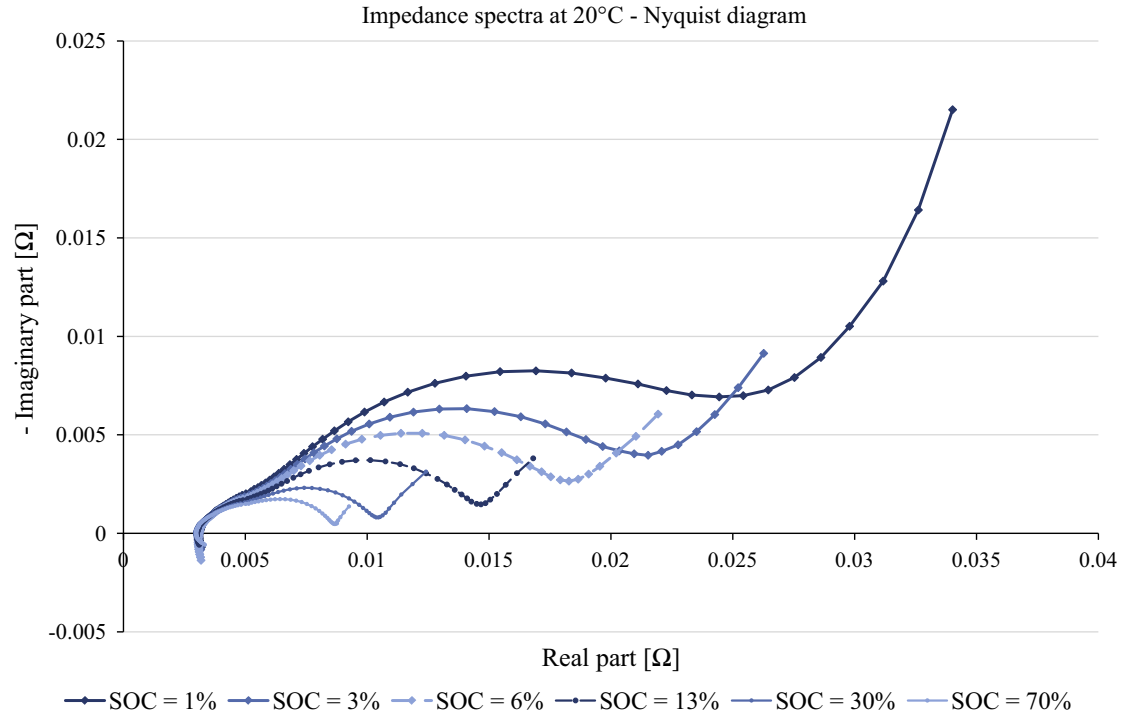

Fig. 13. Impedance spectra (Nyquist plots) at $20^{\circ} \mathrm{C}$ and at several states-of-charge. 


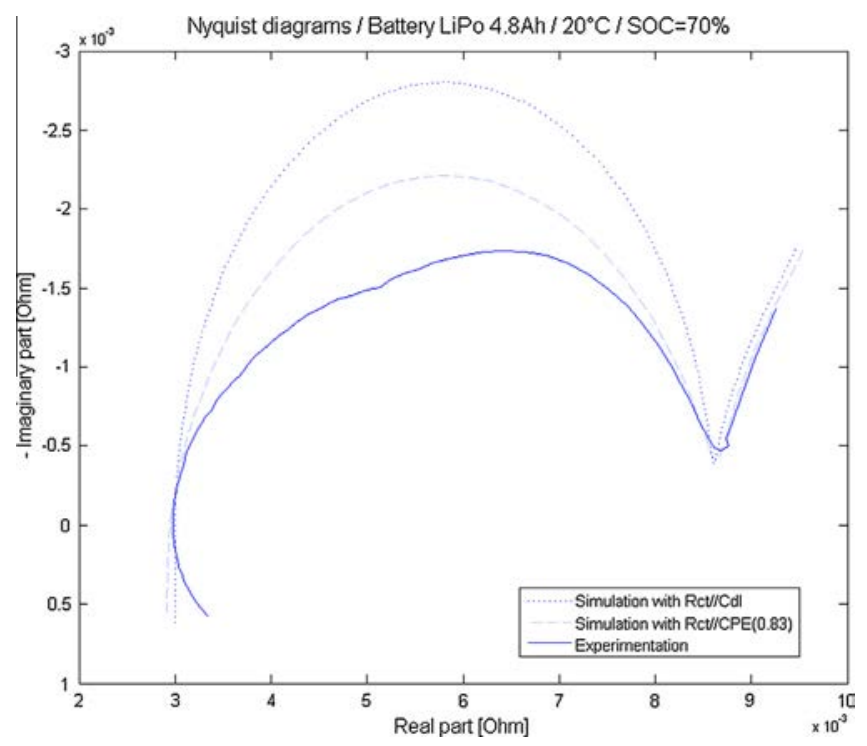

Fig. 15. Comparison between experimentation and simulation results in frequency domain (at $20^{\circ} \mathrm{C}, S O C=70 \%$ ): impedance with $C_{d l}$ versus impedance with $\mathrm{CPE}$.

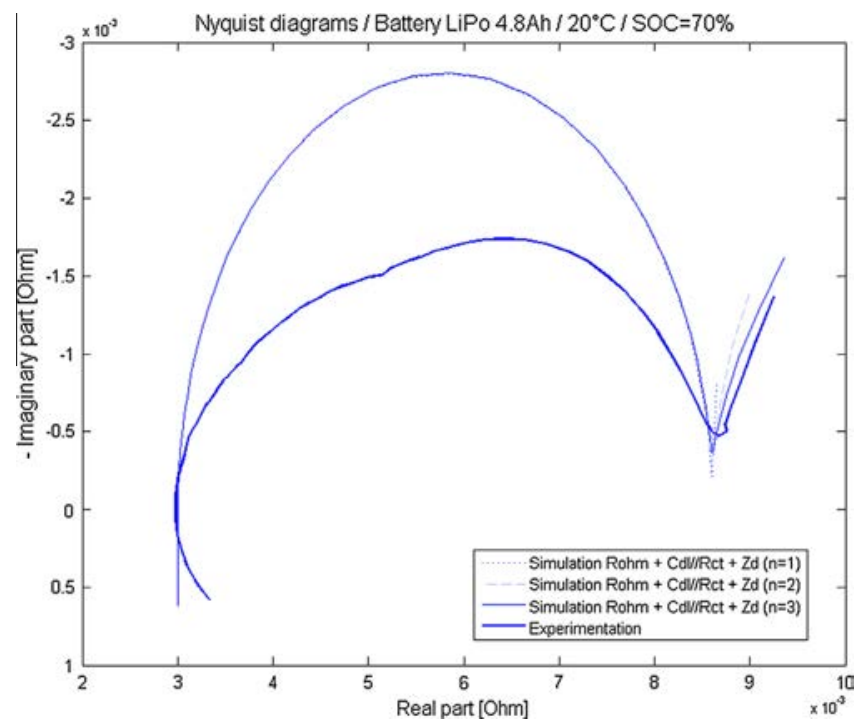

Fig. 16. Comparison between experimentation and simulation results in frequency domain (at $20^{\circ} \mathrm{C}, S O C=70 \%$ ): influence of number of $R-C$ circuits for diffusion impedance.

\section{Results of characterization and simulation}

The impedance spectra are plotted in a complex plane (Nyquist diagram). As the negative area corresponds to the capacitive behavior, the opposite of imaginary part against real part is commonly plotted. In Fig. 13, the impedance spectra at $20^{\circ} \mathrm{C}$ are presented.

Analysis on the modeling of charge transfer and double-layer phenomena. A comparison between experimental impedance spectra and spectra obtained by simulation of the dynamic model with MATLAB ${ }^{\circledR}$ is presented in Fig. 14 . The charge transfer and electric double-layer phenomena are not well-represented by the electrical circuit $R_{c t} / / C_{d l}$. In fact, the gap between impedances obtained by experimentation and by simulation is about $50 \%$ on imaginary part. In order to reduce this significant gap, it is possible to substitute a CPE (Constant Phase Element) for the double-layer
Table 1

Parameters for dynamic model at $20^{\circ} \mathrm{C}$.

\begin{tabular}{lllll}
\hline SOC $(\%)$ & 100 & 70 & 30 & 13 \\
$E_{t h}(\mathrm{~V})$ & 4.2 & 3.88 & 3.72 & 3.54 \\
$L_{f}(\mathrm{nH})$ & 10 & 10 & 10 & 10 \\
$R_{\Omega}(\mathrm{m} \Omega)$ & 3 & 3 & 3 & 3 \\
$R_{c t}(\mathrm{~m} \Omega)$ & 5.24 & 5.68 & 7.51 & 11.65 \\
$C_{d l}(\mathrm{~F})$ & 1.20 & 1.40 & 2.33 & 3.68 \\
$R_{d}(\mathrm{~m} \Omega)$ & 13.6 & 15.2 & 19.6 & 25.3 \\
$\tau_{d}(\mathrm{~s})$ & 110 & 120 & 140 & 175
\end{tabular}

$R_{\Omega}$ is constant whatever $S O C$ is, but is dependent on temperature. $R_{c t}, C_{d l}, R_{d}$ and $\tau_{d}$ are dependent on SOC and temperature.

Table 2

Parameters for dynamic model at $0{ }^{\circ} \mathrm{C}$

\begin{tabular}{lllll}
\hline SOC $(\%)$ & 100 & 84 & 60 & 29 \\
$E_{t h}(\mathrm{~V})$ & 4.2 & 3.99 & 3.83 & 3.71 \\
$L_{f}(\mathrm{nH})$ & 30 & 30 & 10 & 10 \\
$R_{\Omega}(\mathrm{m} \Omega)$ & 3.6 & 3.6 & 3.6 & 3.6 \\
$R_{c t}(\mathrm{~m} \Omega)$ & 26.0 & 27.0 & 30.5 & 42.8 \\
$C_{d l}(\mathrm{~F})$ & 1.07 & 1.28 & 1.38 & 2.27 \\
$R_{d}(\mathrm{~m} \Omega)$ & 10.7 & 13.0 & 15.0 & 30.0 \\
$\tau_{d}(\mathrm{~s})$ & 110 & 130 & 150 & 300 \\
\hline
\end{tabular}

$R_{\Omega}$ is constant whatever SOC is, but is dependent on temperature. $R_{c t}, C_{d l}, R_{d}$ and $\tau_{d}$ are dependent on SOC and temperature.

Table 3

Parameters for dynamic model at $40{ }^{\circ} \mathrm{C}$.

\begin{tabular}{lllll}
\hline SOC $(\%)$ & 100 & 63 & 24 & 10 \\
$E_{t h}(\mathrm{~V})$ & 4.2 & 3.84 & 3.66 & 3.45 \\
$L_{f}(\mathrm{nH})$ & 40 & 40 & 30 & 50 \\
$R_{\Omega}(\mathrm{m} \Omega)$ & 2.8 & 2.8 & 2.8 & 2.8 \\
$R_{c t}(\mathrm{~m} \Omega)$ & 1.01 & 1.25 & 2.05 & 3.01 \\
$C_{d l}(\mathrm{~F})$ & 1.42 & 2.01 & 3.44 & 4.23 \\
$R_{d}(\mathrm{~m} \Omega)$ & 7.2 & 9.0 & 11.0 & 18.0 \\
$\tau_{d}(\mathrm{~s})$ & 75 & 90 & 100 & 150 \\
\hline
\end{tabular}

$R_{\Omega}$ is constant whatever SOC is, but is dependent on temperature. $R_{c t}, C_{d l}, R_{d}$ and $\tau_{d}$ are dependent on SOC and temperature.
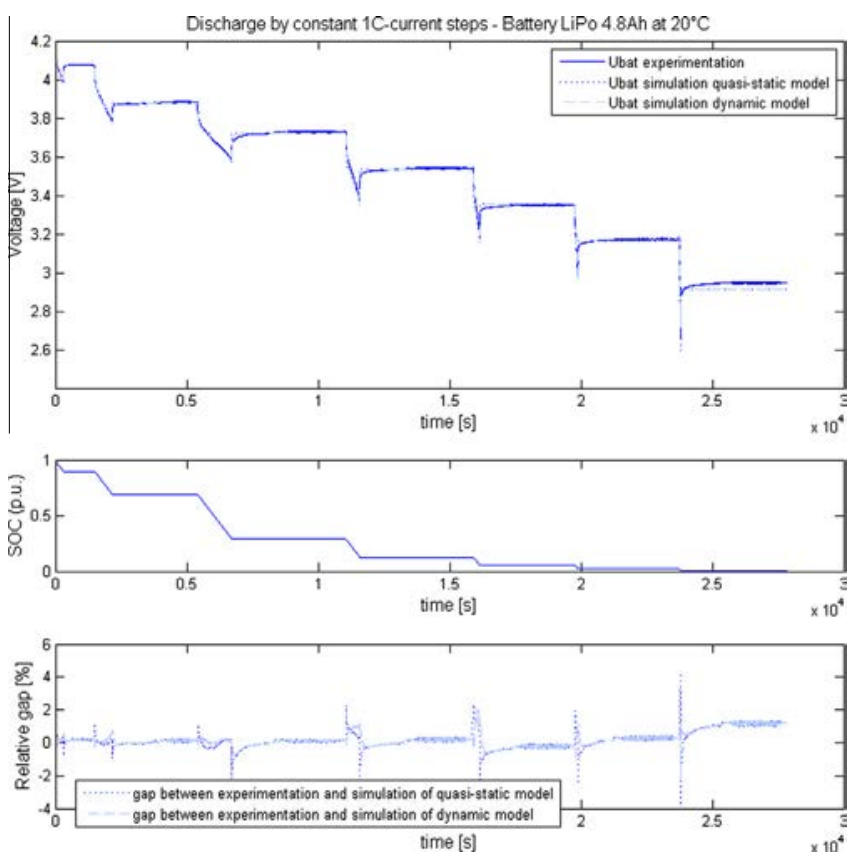

Fig. 17. Comparison between experimentation and simulation results in time domain: discharge test by constant $1 \mathrm{C}$-current steps at $20^{\circ} \mathrm{C}$. 


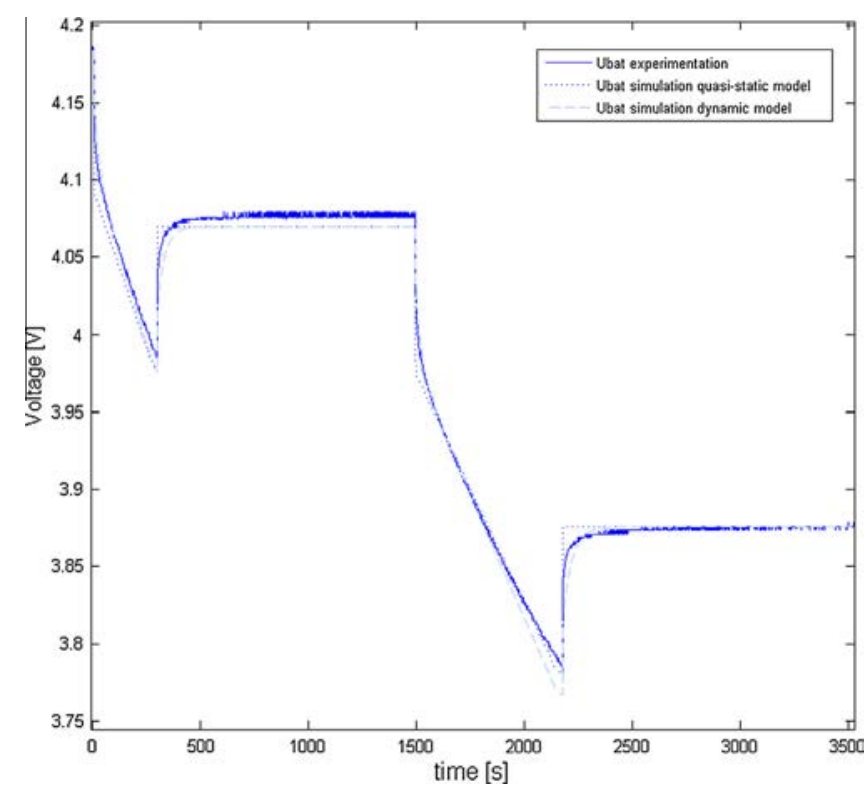

Fig. 18. Comparison between experimentation and simulation results in time domain: discharge test by constant $1 \mathrm{C}$-current steps at $20^{\circ} \mathrm{C}-$ zoom on the 3500 first seconds.

capacitor $C_{d l}$. The impedance of a CPE, in Laplace domain, is given in (8).

$Z_{\mathrm{CPE}}(p)=1 /\left(Q \cdot p^{\gamma}\right)$

where $\gamma$ is the impedance order and $Q$ is a coefficient defined in (9), so that critical pulsations of electrical circuits $R_{c t} / / C_{d l}$ and $R_{c t} / / \mathrm{CPE}$ are the same.

$Q=R_{c t}^{(\gamma-1)} \cdot C_{d l}^{\gamma}$
In Fig. 15 , the experimental spectrum at $20^{\circ} \mathrm{C}$ and for SOC $=70 \%$ is compared to two simulation results: one with the electrical circuit $R_{c t} / / C_{d l}$ and one with a CPE instead of the double-layer capacitor. The lower gap between experimentation and simulation results is obtained with a CPE with an order of 0.83. In that case, the gap equals $22 \%$. For conclusion, the dynamic model is more precise with a CPE instead of the double-layer capacitor. However, this observation is valid in frequency domain. In time domain, the implementation of impedance with non-integer order is very complex. Therefore, for simulation in time domain, the dynamic model integrates the double-layer capacitor $C_{d l}$.

Analysis on the modeling of diffusion phenomenon. The diffusion impedance $Z_{d}$ can be modeled by a finite sum of $R-C$ circuits according to the Foster structure. In Fig. 16, the influence of the number of $R-C$ circuits is studied. The higher is the number of circuits, the smaller is the gap between model simulation and experimentation. The number of $R-C$ circuits must be high enough to have a good precision, but not too high to ensure an easy model implementation. To obtain a gap lower than $5 \%$, the number of circuits must be at least 3 .

Simulation in time domain. The dynamic model, whose parameters are given in Tables $1-3$, is implanted in MATLAB-Simulink ${ }^{\circledR}$ for simulation. A comparison of experimental results and those obtained by simulation of the quasi-static and the dynamic models is given in Fig. 17. Gaps between each model simulation and the experimentation are drawn. The gap corresponding to quasi-static model is lower than $5 \%$, whereas the gap corresponding to dynamic model is lower than $2 \%$. These observations, done at $20^{\circ} \mathrm{C}$, are also valid at $0^{\circ} \mathrm{C}$ and $40^{\circ} \mathrm{C}$. In Fig. 18 , a zoom is carried out on the 3500 first seconds of the discharge test. The difference between quasistatic model and dynamic model can be observed. The dynamic model, with its complex impedance, represents the transient
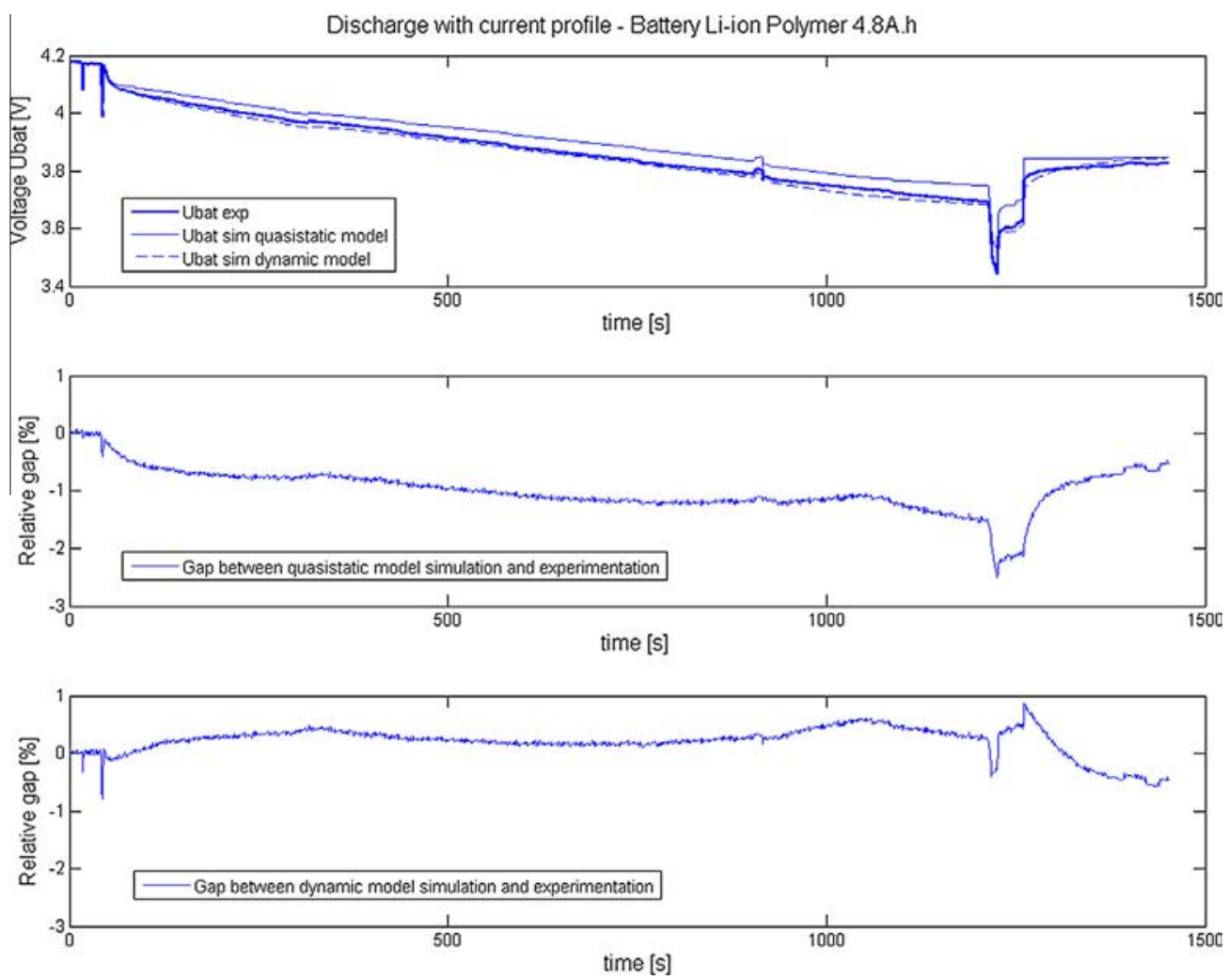

Fig. 19. Comparison between experimentation and simulation results in time domain: discharge test by current profile at $20{ }^{\circ} \mathrm{C}$. 


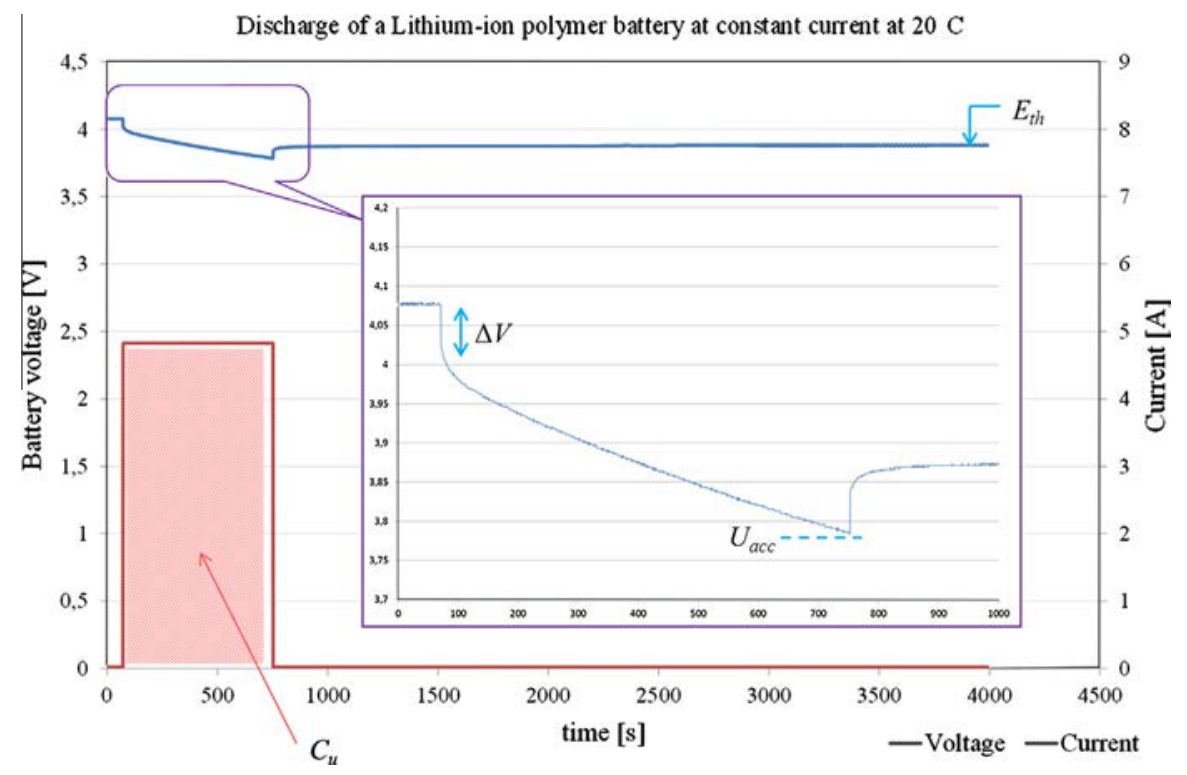

Fig. 20. Evolution of current and voltage during a discharge test at $20^{\circ} \mathrm{C}$ - zoom on voltage evolution for resistance determination.

behavior of battery in a better way than the quasi-static model, whose impedance is an ohmic resistance.

\section{Comparison between simulation and experimentation results on a load profile}

Finally, the simulation of both models is compared to experimentation where the voltage evolution of the battery cell is measured in response to a mission profile (Fig. 19), where current is not constant. As shown previously, the gap between quasi-static model and experimentation is higher than the gap between dynamic model and experimentation: the mean value of the relative gap for the first model is about $1 \%$ and for the second model is about $0.3 \%$. Such a difference is due to the battery impedance which is approached by a pure ohmic resistance in the case of the quasi-static model. The lack of precision of the quasi-static model is all the more remarkable that the current is high.

\section{Discussion}

Beyond the characteristic results of each model, it is interesting to underline the complementarity of the tests for the identification of model parameters.

On the one hand, the charge or discharge tests at high current can be used for determination of time constant concerning diffusion phenomenon. In fact, impedance spectrometry is carried out on the frequency range $\left[20 \cdot 10^{-3} ; 10 \cdot 10^{3}\right] \mathrm{Hz}$. In certain conditions of state-of-charge and of temperature, the diffusion phenomenon is not completely observed at low frequencies and, unfortunately, a spectrometry at lower frequencies takes a lot of time. Therefore, the time constant of diffusion phenomenon can be determined from a discharge test at $1 \mathrm{C}$-current. In this case, the electrical behavior of battery is approached by a first order system response, and the time constant is deduced from the time response to a current step.

On the other hand, the resistance of the quasi-static model can be detailed through EIS results. In the paragraph 2.2, the voltage drop due to serial resistance was observed and seemed to be overrated. The spectrometry results show that several impedances are added to represent the different phenomena inside the battery cell. Thus the internal resistance $R_{b a t}$ can be broken down into several resistances. Actually, the resistance of the quasi-static model is obtained through (3). But it can be determined by considering the voltage drop $\Delta V$, as shown in Fig. 20. In this case, internal resistance $R_{b a t}$ is equivalent to $R_{\Omega}$ of dynamic model, if the acquisition time of measurement is short (lower than $10 \mathrm{~ms}$ ). $R_{b a t}$ can also be compared to $R_{\Omega}+R_{c t}$ if the sample period of test bench is higher than time constant of charge transfer phenomenon (higher than $1 \mathrm{~s})$. Therefore, the comparison between both models and both methods for parameter identification leads to refine parameters and to adjust them when it is necessary.

\section{Conclusion}

One of the aims of this paper was to present two models applied to a Lithium-ion Polymer battery, based on equivalent electrical circuits and adapted to network management and analysis, which can be used for the simulation of embedded network operation.

A quasi-static model and a dynamic model are introduced in this paper because they are the most interesting models to represent the battery steady-state operation and its transient behavior inside a global aircraft network model. A quasi-static model, based on Thevenin model, has been developed. This functional model has been improved by taking into account the influence of stateof-charge and temperature on model parameters. This model is suitable for studies of energy management. However, the lack of precision in representation of transient phenomena is its main drawback. For studies which need more precision, a dynamic model has been developed. Based on the Randles model, the dynamic model is composed of an open-circuit voltage and complex impedance. This impedance represents the charge transfer, the double-layer and the diffusion phenomena. Its parameters were identified by a harmonic analysis of spectra obtained with EIS. The results of dynamic model simulation in time domain are in good agreement with experimental results.

Another aim of this work was to give a complete experimental data for a Lithium-ion Polymer high power cell. Thus, experimentations such as chronopotentiometry at constant current or Electrochemical Impedance Spectroscopy were carried out in different environmental conditions. Both of the characterization methods are useful for the model parameter identification, because they complement one another. In this paper, the results obtained 
with the different tests have been analyzed and compared and the complementarity of these procedures has been demonstrated.

\section{Acknowledgments}

This study has been carried out within the framework of a research program funded by the Direction Générale de l'Armement (French government defense agency).

\section{References}

[1] Roboam X. New trends and challenges of electrical networks embedded in more electrical aircraft. IEEE Int Symp Ind Electron (ISIE) 2011:26-31.

[2] Ibrahim H, Ilinca A, Perron J. Energy storage systems - characteristics and comparisons. Renew Sustain Energy Rev 2008;12:1221-50.

[3] Hall P, Bain E. Energy storage technologies and electricity generation. Energy Policy 2008;36:4352-5.

[4] Vazquez S, Lukic S, Galvan E, Franquelo L, Carrasco J. Energy storage systems for transport and grid applications. IEEE Trans Ind Electron December 2010;57:3881-95.

[5] Kokam, Kokam datasheets [Online] www.kokam.com. [Accessed 2011].

[6] He H, Xiong R, Guo H, Li S. Comparison study on the battery models used for the energy management of batteries in electric vehicles. Energy Convers Manage 2012;64:113-21.

[7] Tsang K, Sun L, Chan W. Identification and modelling of Lithium ion battery. Energy Convers Manage 2010;51:2857-62.

[8] Urbain M, Hinaje M, Raël S, Davat B, Desprez P. Energetical modeling of lithium-ion batteries including electrode porosity effects. IEEE Trans Energy Convers September 2010:25:862-72.

[9] Xie C, Ogden J, Quan S, Chen Q. Optimal power management for fuel cellbattery full hybrid power train on a test station. Electrical Power Energy Syst 2013;53:307-20.
[10] Gomez J, Nelson R, Kalu E, Weatherspoon M, Zheng J. Equivalent circuit model parameters of a high power Li-ion battery: thermal and state of charge effects. J Power Sources May 2011;196:4826-31.

[11] Eddahech A, Briat O, Al Jed H, Chaari R, Mieze A, Simon R, Vinassa J. Li-Po batteries modelling for mail delivery electric vehicles. In: IEEE Vehicle Power and Propulsion Conference (VPPC), Chicago, USA; September 2011.

[12] Plett G-L. Extended Kalman filtering for battery management systems of LiPBbased HEV battery packs - Part 2. Modeling and identification. J Power Sources 2004:134:262-76.

[13] Hentunen A, Lehmuspelto T, Suomela J. Electrical battery model for dynamic simulations of hybrid electric vehicles. In: IEEE Vehicle Power and Propulsion Conference (VPPC), Chicago, USA; September 2011.

[14] Huet F. A review of impedance measurements for determination of state-ofcharge and state-of-health of secondary batteries. J Power Sources 1998;70:59-69.

[15] Lee S, Kim J, Lee J, Cho B-H. State-of-charge and capacity estimation of lithiumion battery using a new open-circuit voltage versus state-of-charge. J Power Sources 2008;185:1367-73.

16] Thévenin L. Extension of Ohm's law to complex electromotive circuits (extension de la loi d'Ohm aux circuits électromoteurs complexes). Annales Télégraphiques 1883;10:222-4.

[17] Bernard J, Hofer M, Hannesen U, Toth A, Tsukada A, Buchi F, et al. Fuel cell/ battery passive hybrid power source for electric powertrains. J Power Sources 2011;196:5867-72.

[18] Camara M, Gualous H, Gustin F, Berthon A. Design and new control of DC/DC converters to share energy between supercapacitors and batteries in hybrid vehicles. IEEE Trans Vehicular Technol September 2008;57:2721-35.

[19] Randles J.-E.-B. Kinetics of rapid electrode reactions. Discussions of the Faraday Society, 1947.

[20] Kuhn E, Forgez C, Lagonotte P, Friedrich G. Modelling Ni-MH battery using Cauer and Foster structures. J Power Sources August 2006;158:1490-7.

[21] Mauracher P, Karden E. Dynamic modelling of lead-acid batteries using impedance spectroscopy for parameter identification. J Power Sources 1997:67:69-84. 